\title{
Benign familial mesial temporal lobe epilepsy
}

INSERM

\section{Source}

INSERM. (1999). Orphanet: an online rare disease and orphan drug data base. Benign familial mesial temporal lobe epilepsy. ORPHA:163717

Benign familial mesial temporal lobe epilepsy is a rare epilepsy characterized by seizures with viscerosensory or experential auras, onset in adolescence or early adulthood and good prognosis. It is defined as at least 24 months of seizure freedom with or without antiepileptic medication. 